\title{
Functional properties of dietary fibre prepared from defatted rice bran
}

\begin{abstract}
Acumulating evidence favours the view that increased intake of dietary fibre in an otherwise low-fibre diet can have beneficial effects in both human and experimental animals. These benefits include prevention or alleviation of maladies such as cardiovascular disease, diabetes, diverticulosis and colon cancer. Studies have repeatedly shown that rice bran gives interesting health benefits. Compositional analysis reveals that rice bran consists of almost $27 \%$ dietary fibre and has been reported to have positive effects, such as laxative and cholesterol-lowering ability. This suggests that rice bran is a good fibre source that can be added to various food products. This paper examines the use of a dietary fibre preparation, derived from defatted rice bran, as a functional ingredient added to bakery products. The results show that dietary fibre from defatted rice bran has comparable water-binding capacity to FIBREX, commercial fibre from sugar beet. Dietary fibre from rice bran exhibited higher fat binding and emulsifying capacity compared to FIBREX. However, rice bran fibre was found to be less viscous than FIBREX. Addition of 5 and $10 \%$ dietary fibre preparation reduced loaf volume significantly and increased the firmness of the breads. Sensory evaluations revealed that breads with 5 and $10 \%$ rice bran fibre were comparable to highfibre bread available in the market. This confirms that the dietary fibre preparation from defatted rice bran has great potential in food applications, especially in development of functional foods.
\end{abstract}

Keyword: Dietary fiber; Rice bran; Food composition; Food quality 